\title{
Meeting report of the 49th annual meeting of the European Histamine Research Society (EHRS)
}

\author{
Linda Kay ${ }^{1} \cdot$ Ilona Obara ${ }^{2} \mathbb{D}$
}

Received: 26 July 2020 / Revised: 26 July 2020 / Accepted: 4 August 2020 / Published online: 11 August 2020

(c) Springer Nature Switzerland AG 2020

\begin{abstract}
The 49th annual meeting of the European Histamine Research Society (EHRS) was planned to be held at 'Die Wolfsburg', Mühlheim an der Ruhr near Düsseldorf in Germany. With the announcement of the COVID-19 pandemic, the face-to-face conference meeting was cancelled and instead, the EHRS Council proposed an Online Symposium to keep up the good spirits and research enthusiasm of the Society members. This meeting report summarises two $2 \mathrm{~h}$ sessions held on 1st and 2nd July, 2020 and delivered via Blackboard Collaborate. The Online Symposium covered a range of interesting and inspiring topics around the molecular and clinical pharmacology of histamine, with nine exciting presentations delivered by young and senior members of the Society across both days.
\end{abstract}

The European Histamine Research Society (EHRS) brings together researchers of all career levels from many different disciplines, including chemists, pharmacologists, physiologists, biologists, pharmacists and clinicians who are all interested in histamine. The aim of the Society is to promote knowledge and research within all aspects of histamine and related fields as well as gathering new information about histamine, encourage publications and stimulate contacts and collaborations between scientists across the world. The Society meets annually at scientific conferences organised by its members for nearly 50 years with the first meeting being held in 1971 in Paris, France.

This year's meeting was planned to be held at 'Die Wolfsburg', Mühlheim an der Ruhr near Düsseldorf (Germany) at the kind invitation of Holger Stark and colleagues. With the announcement of the COVID-19 pandemic by WHO in March 2020, the face-to-face conference meeting was cancelled and instead, the EHRS Council proposed an Online

Responsible Editor: John Di Battista.

Ilona Obara

ilona.obara@ncl.ac.uk

1 Department of Infection, Immunity and Cardiovascular Disease, Faculty of Medicine, Dentistry and Health, University of Sheffield, Sheffield, UK

2 School of Pharmacy and Translational and Clinical Research Institute, The Faculty of Medical Sciences, Newcastle University, King George VI Building, Newcastle upon Tyne NE1 7RU, UK
Symposium to keep up the good spirits and research enthusiasm of the Society members.

Ilona Obara (Newcastle University, Newcastle upon Tyne, UK), Astrid Sasse (Trinity College Dublin, Dublin, Ireland), Holger Stark (Heinrich Heine University Düsseldorf, Düsseldorf, Germany) and Ekaterina Tiligada (National and Kapodistrian University of Athens, Athens, Greece) organized two $2 \mathrm{~h}$ sessions held on 1st and 2nd July 2020 using Blackboard Collaborate as a platform. Even though this was an innovative challenge for organizers and participants, the sessions ran smoothly on both days (apart from a few technical glitches) and can be streamed from our website: https:// www.ehrs.org.uk/.

There were 102 participants on the first day and 78 participants on the second day of the Symposium. Participants attended from most of the European countries, the Americas, Middle and Far East. Some regular attendees and members of the Society could not participate and they were hugely missed, but a big welcome was made to all the new participants, who will hopefully return to future meetings of our Society.

The Online Symposium covered a range of interesting and inspiring topics around the molecular and clinical pharmacology of histamine, with nine exciting presentations delivered by young and senior members of the Society across both days.

The first session, 'Molecular and Clinical Pharmacology Part 1', chaired by João Paulo Fernandes (Universidade Federal de São Paulo, Diadema, SP, Brazil) and Susanne 
Mommert (Hannover Medical School, Hannover, Germany) took place on 1st July, 2020 (13:00-15:00 CEST), starting with a warm welcome and opening from our president, Ekaterina Tiligada. She thanked the organizers, particularly the Trinity College Dublin for providing the platform for the Symposium and Astrid Sasse (Trinity College Dublin, Dublin, Ireland) for technical support and guidance that made the Symposium possible. She then outlined the programme for both days. The scientific session started with a plenary talk from Madeleine Ennis (The Queen's University of Belfast, Belfast, UK) who addressed a very current and highly interesting topic associated with clinical trials to combat COVID-19. She outlined and critiqued the available evidence (from popular press and internet) suggesting that Famotidine (histamine $\mathrm{H}_{2}$ receptor antagonist) may be helpful in the treatment of COVID-19. Drug repurposing/computational biology studies have suggested that also other drugs might be potential treatments. These include $\mathrm{H}_{1}$ antagonists (Chlorpheniramine, Terfenadine), $\mathrm{H}_{2}$ antagonists (Famotidine, Cimetidine), mast cell stabilizer (Cromolyn), 5-lipoxygenase inhibitor (Setileuton) and leukotriene receptor antagonist (Montelukast). However, to date it appears that Famotidine has no direct antiviral activity on SARS-CoV-2. In addition, $\mathrm{H}_{2}$ antagonists are immunomodulators, but further studies are needed to see if this is important in COVID-19 treatment. The next oral presentation, from Dr Ling Shan (Netherlands Institute for Neuroscience, Amsterdam, The Netherlands), proposed a new therapeutic strategy using histamine $\mathrm{H}_{4}$ receptor antagonist to inhibit pro-inflammatory microglia and prevent the progression of Parkinson-like pathology. Next, were three oral presentations from young members of our Society. The first presenter was Ibrahim Alrashdi (Newcastle University, Newcastle upon Tyne, UK) who provided us with new evidence for an important involvement of peripheral histamine $\mathrm{H}_{1}$ and central histamine $\mathrm{H}_{4}$ receptors, in the regulation of histaminergic itch. Xiaoyuan Ma (Vrije Universiteit Amsterdam, Amsterdam, The Netherlands) then spoke about the pharmacological impact of missense variants in human histamine $\mathrm{H}_{1}$ receptor. The last presentation of the day, from Maria Kakolyri (National and Kapodistrian University of Athens, Athens, Greece) was about the cross-talk of basal plasma histamine levels and the pharmacological properties of the drug in NSAID-induced hypersensitivity reactions.

The second session, 'Molecular and Clinical Pharmacology Part 2', chaired by Wiesława Agnieszka Fogel (Medical University of Lodz, Lodz, Poland) and Pertti Panula (University of Helsinki, Helsinki, Finland) was held the following day (13:00-15:00 CEST) and was centred around the $\mathrm{H}_{3}$ receptor. The session started with a plenary talk from Yves Auberson (Novartis Institutes for BioMedical Research, Basel, Switzerland) who spoke about the $\mathrm{H}_{3}$ receptor and its role in narcolepsy. He described the optimization work that led to the evaluation of three independent chemical series and ultimately to the discovery of the clinical development candidate 1-(1-methyl-6-oxo-1,6-dihydropyridazin3-yl)piperidin-4-yl 4-cyclobutylpiperazine-1-carboxylate, LML134 a histamine $\mathrm{H}_{3}$ receptor inverse agonist, for the treatment of excessive sleep disorders. He spoke about the early clinical profile of LML134 referring to adequate PK and a good safety profile at pharmacologically active doses. The plenary talk was again followed by three oral presentations from young members of our Society. The first presentation was from Cecilia M.S.Q. Aranha (Universidade Federal de São Paulo, Diadema-SP, Brazil) who showed us results indicating that LINS05 compounds may be promising multitarget agents for screening assessment of histamine $\mathrm{H}_{3}$ and dopamine $\mathrm{D}_{3}$ as well as acetylcholinesterase. Then, David Reiner (Heinrich Heine University Düsseldorf, Düsseldorf, Germany) spoke about histone H3 methyltransferases and histamine $\mathrm{H}_{3}$ receptors as combined targets for Prader-Willi syndrome. The last presentation was from Mohamed Alawad (United Arab Emirates University, Abu Dhabi, United Arab Emirates) who showed data supporting effect of histamine $\mathrm{H}_{3}$ and dopamine $\mathrm{D}_{2} / \mathrm{D}_{3}$ receptors antagonist ST-713 on autism-like behavioural features in BTBR $\mathrm{T}+\mathrm{tf} / \mathrm{J}$ mice.

At the end of the final session, our president Ekaterina Tiligada, thanked both the young and senior scientists for two inspiring days of talks ranging from topics about new compounds to the many novel and exploitable actions of histamine. Her thanks also went out to the organisers, both the Scientific and Bursary Award Committee, invited speakers and the sponsor, Trinity College Dublin (Ireland). To end the meeting, a short recording of the EHRS anthem from a previous meeting was played, as we were not together in person to sing it.

We would like to highlight that the majority of the Online Symposium presentations were given by young members of our Society, who were able to share with us their research findings despite the challenge of adapting our lives to the new measures set by the COVID-19 pandemic, and unfortunate cancelation of the conference in Germany. We decided to award their dedication and enthusiasm to science by giving a Bursary Award towards next year's 50th Annual EHRS Meeting. This year's Bursary Award Committee was formed by Dorota Lazewska (Jagiellonian University Medical College, Krakow, Poland), Mitsunobu Mio (Shujitsu University, Okayama, Japan, Chair of the Committee) and Olga Sergeeva (Heinrich Heine University Düsseldorf, Düsseldorf, Germany). They assessed all presentations based on quality, innovation of science and response of the presenter to questions. It was rather a difficult task for the judges in differentiating between these six excellent presentations. The first prize went to David Reiner (Germany) with both Cecilia M.S.Q. Aranha (Brazil) and Xiaoyuan Ma (The Netherlands) as runners up. 
Finally, our thanks are given to all of the organizers for bringing us together in this unprecedented time. The next meeting, which will be the 50th Anniversary EHRS Meeting, will be held in Hannover, Germany. It will be jointly organized by Thomas Werfel, Holger Stark and their colleagues. The proposed dates are set for 6-8 May 2021 with further information being shared via our website: https:// www.ehrs.org.uk/.

Publisher's Note Springer Nature remains neutral with regard to jurisdictional claims in published maps and institutional affiliations. 